Research Paper

\title{
Glucose-6-Phosphate Dehydrogenase (G6PD) Deficiency and Late-stage Age-Related Macular Degeneration
}

Antonio Pinna ${ }^{1,3 凶}$, Giuliana Solinas², Ermete Giancipoli², Tiziana Porcu루, Angelo Zinellu², Giuseppe D' Amico-Ricci'2, Francesco Boscia ${ }^{1,3}$, Paolo Lanzetta ${ }^{4}$, Teresio Avitabile ${ }^{5}$, Arthur G. Schwartz ${ }^{6}$, Ciriaco Carru $2,3 \bowtie$

1. Department of Medical, Surgical, and Experimental Sciences, University of Sassari, Sassari, Italy

2. Department of Biomedical Sciences, University of Sassari, Sassari, Italy

3. Azienda Ospedaliero-Universitaria di Sassari, Sassari, Italy

4. Department of Medicine - Ophthalmology, University of Udine, Udine, Italy

5. Department of Ophthalmology, University of Catania, Catania, Italy

6. Fels Institute for Cancer Research and Molecular Biology, Temple University School of Medicine, Philadelphia, Pennsylvania, USA

$\triangle$ Corresponding author: Antonio Pinna, MD, Department of Medical, Surgical, and Experimental Sciences, Ophthalmology Unit, University of Sassari, Viale San Pietro 43 A, 07100 Sassari, Italy. Phone: +39 079228251. Fax: +39 079228484. E-mail: apinna@uniss.it

(C) Ivyspring International Publisher. This is an open access article distributed under the terms of the Creative Commons Attribution (CC BY-NC) license (https://creativecommons.org/licenses/by-nc/4.0/). See http://ivyspring.com/terms for full terms and conditions.

Received: 2018.09.24; Accepted: 2018.12.07; Published: 2019.05.07

\begin{abstract}
Purpose: Age-related macular degeneration (AMD) is the leading cause of blindness in the elderly in Western Countries. Evidence indicates that Glucose-6-Phosphate Dehydrogenase (G6PD) deficiency, a common genetic abnormality, may protect against ischemic heart and cerebrovascular disease, ocular vascular disorders, and colorectal cancer. This study was undertaken to ascertain whether G6PD deficiency may protect against AMD.

Materials and Methods: 79 men with late-stage AMD and 79 male, age-matched cataract controls without AMD were recruited in March-December 2016. Smoking status, clinical history, and drug use were recorded. A blood sample was taken from each participant. Complete blood count, hemoglobin, glucose, creatinine, cholesterol, triglycerides, transaminases, bilirubin, and erythrocyte G6PD activity were measured. Stepwise logistic regression was used to investigate the association between G6PD deficiency and AMD.

Results: G6PD deficiency was found in 7 (8.9\%) AMD patients and $8(10.1 \%)$ controls, a not statistically significant difference. Stepwise logistic regression disclosed that AMD was significantly associated with increased diastolic blood pressure $(\mathrm{OR}=1.09,95 \% \mathrm{Cl}=1.03-1.15, \mathrm{P}=0.02)$ and LDL-cholesterol $(\mathrm{OR}=1.02,95 \% \mathrm{Cl}=1.0001-1.03, \mathrm{P}=0.049)$ and lower values of white blood cell (WBC) count (OR=0.71, 95\% Cl=0.56-0.88, $\mathrm{P}=0.02)$ and aspartate aminotransferase (AST) (OR=0.92, 95\% Cl=0.85-0.99, $\mathrm{P}=0.044)$.

Conclusion: Results suggest that G6PD deficiency has no protective effect on nor is a risk factor for AMD. Larger studies are necessary to confirm whether increased diastolic blood pressure and LDL-cholesterol and lower values of WBC count and AST are risk factors for AMD.
\end{abstract}

Key words: age-related macular degeneration (AMD); Glucose-6-Phosphate Dehydrogenase (G6PD) deficiency; observational case-control study; stepwise logistic regression analysis

\section{Introduction}

Age-related macular degeneration (AMD) is a leading cause of severe, irreversible vision impairment in adults aged over 50 in the Western
Countries. ${ }^{1}$ AMD can be classified into early and late stages. Early AMD is a clinical condition without clearly evident visual symptoms, characterized by 
retinal pigment epithelium alterations and/or drusen in the macular area. ${ }^{2}$ The late-stage manifestations of AMD include geographic atrophy (dry AMD) and neovascolar (wet) AMD. The hallmark of wet AMD is the presence of choroidal neovascularization $(\mathrm{CNV})$, defined as formation of pathological neovessels originating from the choroidal vasculature and extending through a defect in the Bruch's membrane. The pathological mechanisms underlying AMD are not clear, but clinical and experimental evidence indicates that genetic predisposition and environmental factors, such as tobacco smoking and oxidative stress, may play a major role..$^{3-9}$

Glucose-6-Phosphate Dehydrogenase (G6PD) is a ubiquitous cytoplasmic enzyme converting glucose-6-phosphate into 6-phosphogluconate in the pentose phosphate pathway. G6PD is the rate-limiting enzyme of this metabolic pathway that supplies reducing energy to cells by maintaining the level of the reduced form of the extramitochondrial Nicotine-Adenosine-Dinucleotide Phosphate (NADPH) coenzyme. In red blood cells, defense against oxidative stress is strictly dependent on G6PD activity, because the G6PD/NADPH pathway is the only source of reduced glutathione (GSH). ${ }^{10}$ The gene encoding G6PD is on the distal long arm of the $\mathrm{X}$ chromosome (band Xq28). Hemizygous males have populations of uniformly deficient erythrocytes, whereas heterozygous females have mosaic populations of normal and G6PD-deficient red blood cells, due to random inactivation of $\mathrm{X}$ chromosome. G6PD deficiency is genetically heterogeneous and about 400 different variant enzymes have been described. ${ }^{11}$ The G6PD-Mediterranean variant ( $\mathrm{C}$ to $\mathrm{T}$ transition at nucleotide 563) is associated with undetectable levels of enzyme activity by routine methods (WHO class II). This variant is common in the island of Sardinia, Italy, where the reported prevalence of G6PD deficiency is 8-15\%.12-18 G6PD deficiency represents a public health issue in Sardinia, because of the seasonal occurrence of favism, a hemolytic anemia caused by the ingestion of the broad bean (Vicia faba) in affected subjects. ${ }^{11,13}$

Former studies have suggested that G6PD deficiency may have a protective effect on ischemic heart and cerebrovascular disease and colorectal cancer. ${ }^{14,19,20}$ Additionally, G6PD-deficient individuals have been reported to have a significantly decreased risk of developing retinal vein occlusion (RVO) and nonarteritic anterior ischemic optic neuropathy (NAION). ${ }^{16,21}$ The concept that G6PD deficiency may protect against the development of various age-related diseases is new and not yet established.

Little is known about the role of G6PD deficiency in AMD. The present study was designed to assess the frequency of G6PD deficiency in Sardinian men with AMD and ascertain whether G6PD deficiency is a risk factor for AMD or may have a protective effect against this important cause of blindness in the elderly.

\section{Patients and Methods}

The present study used a case-control design, recruiting 79 consecutive men with late-stage AMD and 79 perfectly age-matched male controls without AMD between March and December 2016. Women were excluded because of the small number of homozygote subjects with complete lack of erythrocyte G6PD activity. Sample size was computed before the survey, using a two-tailed test at 5\% significance level with an $80 \%$ statistical power to detect an estimated relative risk of 0.4 , assuming a G6PD prevalence rate of $8 \%$ as reported previously, 13,17,18 and an incidence of 25,000 new AMD cases per year (data from the Istituto Nazionale di Statistica - ISTAT, 2004, Italy).

Institutional ethics review board approval was obtained and the study was conducted in full accord with the tenets of the Declaration of Helsinki. Each participant received detailed information and provided informed consent before inclusion.

The inclusion criteria for cases were male gender, Sardinian descent, and the diagnosis of late-stage AMD (neovascular AMD or geographic atrophy involving the center of the macula) in at least one eye. ${ }^{2}$ All AMD patients underwent a full ophthalmic evaluation, including fluorescein angiography and OCT scans of the macula (3D OCT-1000 Mark II, Topcon Co, Tokyo, Japan).

Perfectly age-matched male controls of Sardinian ancestry were selected among patients undergoing cataract surgery. All controls underwent standard ophthalmic evaluation, including best corrected visual acuity, slit-lamp examination, applanation tonometry, and fundus examination. Patients with any clinical evidence of maculopathy (i.e. early, dry or wet AMD, cystoid macular edema, epiretinal membrane, retinal pigment epithelium changes, central serous chorioretinopathy, diabetic macular edema, etc.) and/or retinal vascular disorder (retinal vein occlusion, diabetic retinopathy, etc.) were excluded.

Medical conditions, including body mass index (BMI), systemic hypertension, hypercholesterolemia, diabetes mellitus, cardio- and cerebro-vascular status (positive history of angina, myocardial infarction, TIA, stroke), renal failure, and medication use were also recorded for both AMD patients and controls. Definitions of systemic hypertension, diabetes, and hypercholesterolemia have been reported previously. ${ }^{16}$ 
Smoking history was obtained by an interviewer-administered questionnaire. Current smoking status was compared with noncurrent smoking (individuals who smoked in the past or never smoked).

Sitting blood pressure was measured three times after resting for at least 5 minutes. The average of the three measurements was used for the analysis.

A blood sample was taken from each participant after an overnight fast. Standard laboratory tests, including complete blood count, hemoglobin, glucose, creatinine, total cholesterol, HDL-cholesterol, LDL-cholesterol, triglycerides, transaminases (ALT and AST), and bilirubin were performed. Red blood cell G6PD activity was determined using a quantitative assay (G6PD/6PGD, Biomedic snc, Sassari, Italy), as described previously. ${ }^{16}$

In addition, serum vitamin B12 and folate levels were measured in all patients with AMD. Vitamin B12 and folate were measured using an IMX Analyzer (Abbott Laboratories Diagnostics Division, Abbott Park, IL). The IMX B12 assay is based on the microparticle enzyme immunoassay (MEIA) technology, while IMX folate is an ion capture assay technique. For these immunological assays, inter- and intra-assay coefficients of variation were $<10 \%$. Normal values for plasma vitamin B12 and folate are $179-1162 \mathrm{pg} / \mathrm{ml}$ and $2.7-34 \mathrm{ng} / \mathrm{ml}$, respectively.

Descriptive analysis was performed for all variables measured. Categorical variables were compared by $\mathrm{Z}$ test for proportions and differences for quantitative variables were analyzed by Student's t test.

Stepwise logistic regression models were performed to calculate the estimates of odds ratios (ORs), considering AMD as dependent variable and including BMI, systolic blood pressure, diastolic blood pressure, blood glucose, creatinine, total cholesterol, LDL, HDL, triglycerides, white blood cell (WBC) count, hemoglobin, ALT and AST, bilirubin, G6PD deficiency, smoking status, concomitant cardioand cerebro-vascular disorders (Yes/No), and use of antiplatelet and/or anticoagulant medications (Yes/No) and lipid-lowering drugs (Yes/No) as covariates (full model). Furthermore, interaction terms were added to the regression models to detect possible confounders. A significance level of 0.2 was used to remove covariates from the multivariable model. ORs and 95\% confidence intervals (CIs) were obtained by a maximum likelihood estimation. $\mathrm{P}$ values $<0.05$ were considered to be statistically significant. Statistical analysis was performed with commercial software (STATA ver. 12; StataCorp, College Station, TX).

Four percent of the AMD cases and 7\% of the control subjects who were eligible for the study declined to participate. The major reason was "not interested."

\section{Results}

The study group consisted of 79 AMD men (mean age: $78 \pm 7$ years, range $57-92$ years). The control group included an equal number of perfectly age-matched male subjects without AMD. In both groups, all individuals were of Sardinian ancestry.

In the AMD group, 19 patients had bilateral wet AMD, 1 bilateral geographic atrophy, 3 wet AMD in one eye and geographic atrophy in the fellow one, and 56 wet AMD in one eye and early AMD in the fellow eye.

Wet AMD patients had received an average of 5 intravitreal injections of an anti-VEGF agent (bevacizumab, ranibizumab, or aflibercept) per eye.

The AMD and cataract groups had identical mean intraocular pressure values $(14 \pm 2.6 \mathrm{~mm} \mathrm{Hg}$ and $14 \pm 3.5 \mathrm{~mm} \mathrm{Hg}$ ). Four (5\%) AMD and $7(9 \%)$ cataract patients had glaucoma, a not statistically significant difference.

Demographics, medical history information, and blood test results are summarized in Table 1. All the diabetic patients had type 2 diabetes. Both AMD patients and control subjects had similar rates of diabetes, hypertension, hypercholesterolemia, cardioand cerebro-vascular disorders, chronic renal failure, G6PD deficiency, smoking, and use of antiplatelet and/or anticoagulant medications and lipid-lowering drugs. Likewise, there were no significant differences in BMI, hemoglobin, plasma glucose, creatinine, LDL, triglycerides, ALT, and bilirubin values. On the other hand, AMD patients had significantly higher values of systolic and diastolic blood pressure, plasma cholesterol, and HDL, and significantly lower values of WBC count and AST.

Mean plasma vitamin B12 and folate values in AMD patients fell within normal ranges $(299 \mathrm{pg} / \mathrm{ml}$ and $5.2 \mathrm{ng} / \mathrm{ml}$, respectively).

Forward-stepwise selection led to a final logistic regression model with 8 variables, including diastolic blood pressure, LDL, HDL, WBC count, hemoglobin, AST, smoking status, and concomitant cardio- and cerebro-vascular disorders (Yes/No). In this model, logistic regression analysis showed that AMD was significantly associated with higher values of diastolic blood pressure $(\mathrm{OR}=1.09,95 \% \mathrm{CI}=1.03-1.15, \mathrm{P}=$ $0.02)$ and $\mathrm{LDL}(\mathrm{OR}=1.02,95 \% \mathrm{CI}=1.0001-1.03, \mathrm{P}=$ $0.049)$ and lower values of $\mathrm{WBC}$ count $(\mathrm{OR}=0.71,95 \%$ $\mathrm{CI}=0.56-0.88, \mathrm{P}=0.02)$ and $\mathrm{AST}(\mathrm{OR}=0.92,95 \% \mathrm{CI}=$ $0.85-0.99, P=0.044)$. No interaction term was found to be statistically significant. 
Table 1. Demographics, medical history information, and blood test results of patients with age-related macular degeneration (AMD) and cataract controls without AMD.

\begin{tabular}{|c|c|c|c|}
\hline & AMD patients $(n=79)$ & Controls $(n=79)$ & P values (Cases vs Controls) \\
\hline Systemic hypertension, $\mathrm{n}(\%)^{*}$ & $55(69.6)$ & $51(64.6)$ & 0.5 \\
\hline Diabetes mellitus, $n(\%) \dagger$ & $14(17.7)$ & $20(25.3)$ & 0.25 \\
\hline Hypercholesterolemia, $n(\%) \ddagger$ & $37(46.8)$ & $42(53.2)$ & 0.43 \\
\hline Body mass index $\left(\mathrm{kg} / \mathrm{cm}^{2}\right)$, mean $\pm \mathrm{SD}$ & $27.2 \pm 5.5$ & $27.1 \pm 3.7$ & 0.84 \\
\hline Cardiovascular and Cerebrovascular disease, n (\%) & $11(13.9)$ & $10(12.7)$ & 0.82 \\
\hline Chronic renal failure & $3(3.8)$ & $2(2.5)$ & 0.65 \\
\hline G6PD deficiency, $n(\%)$ & $7(8.9)$ & $8(10.1)$ & 0.79 \\
\hline Smoking, $n(\%)$ & $11(8.7)$ & $11(8.7)$ & 1 \\
\hline Systolic blood pressure $(\mathrm{mm} \mathrm{Hg})$, mean \pm SD & $141.2 \pm 18.4$ & $134.1 \pm 14.4$ & 0.0075 \\
\hline Diastolic blood pressure $(\mathrm{mm} \mathrm{Hg})$, mean \pm SD & $80.6 \pm 9.3$ & $76.1 \pm 9.9$ & 0.0039 \\
\hline White blood cell count $\left(\times 10^{3} / \mu \mathrm{L}\right)$ & $7.0 \pm 1.9$ & $7.99 \pm 2.4$ & 0.0073 \\
\hline Hemoglobin $(g / d L)$, mean \pm SD & $14.0 \pm 1.62$ & $14.0 \pm 2.2$ & 0.99 \\
\hline Plasma glucose $(\mathrm{mg} / \mathrm{dL})$, mean $\pm \mathrm{SD}$ & $107.8 \pm 23.4$ & $121.1 \pm 57.4$ & 0.06 \\
\hline Total cholesterol $(\mathrm{mg} / \mathrm{dL})$, mean $\pm \mathrm{SD}$ & $193.3 \pm 35.6$ & $178.6 \pm 42.5$ & 0.02 \\
\hline $\mathrm{HDL}(\mathrm{mg} / \mathrm{dL})$, mean $\pm \mathrm{SD}$ & $54.7 \pm 12.1$ & $49.3 \pm 12.3$ & 0.0055 \\
\hline $\mathrm{LDL}(\mathrm{mg} / \mathrm{dL})$, mean $\pm \mathrm{SD}$ & $116 \pm 35.2$ & $105.0 \pm 38.4$ & 0.0643 \\
\hline Triglycerides $(\mathrm{mg} / \mathrm{dL})$, mean $\pm \mathrm{SD}$ & $103.5 \pm 53.3$ & $117.6 \pm 58.4$ & 0.11 \\
\hline Creatinine $(\mathrm{mg} / \mathrm{dL})$, mean $\pm \mathrm{SD}$ & $0.9 \pm 0.4$ & $1.07 \pm 0.6$ & 0.06 \\
\hline $\operatorname{ALT}(\mathrm{U} / \mathrm{L})$, mean $\pm \mathrm{SD}$ & $16.6 \pm 7.7$ & $19.8 \pm 14.2$ & 0.08 \\
\hline AST $(\mathrm{U} / \mathrm{L})$, mean $\pm \mathrm{SD}$ & $18.3 \pm 6.2$ & $22.4 \pm 12.2$ & 0.0075 \\
\hline Bilirubin $(\mathrm{mg} / \mathrm{dL})$, mean $\pm \mathrm{SD}$ & $0.8 \pm 0.4$ & $0.9 \pm 0.5$ & 0.09 \\
\hline Antiplatelet and/or anticoagulant drug use, n (\%) & $28(35.4)$ & $28(35.4)$ & 1 \\
\hline Use of lipid-lowering drugs, n (\%) & $24(30.4)$ & $27(34.2)$ & 0.61 \\
\hline
\end{tabular}

* Blood pressure $\geq 140 \mathrm{~mm} \mathrm{Hg}$ systolic or $\geq 90 \mathrm{~mm} \mathrm{Hg}$ diastolic or taking antihypertensive medication.

† Fasting plasma glucose $\geq 126 \mathrm{mg} / \mathrm{dL}$ and/or plasma glucose $\geq 200 \mathrm{mg} / \mathrm{dL} 2$ hours after a 75 -g oral glucose load or taking insulin or oral hypoglycemics.

$\ddagger$ Fasting plasma cholesterol $\geq 220 \mathrm{mg} / \mathrm{dL}$ or taking lipid-lowering drugs.

\section{Discussion}

G6PD deficiency is the most common enzyme deficiency in humans, with an estimated 400 million people affected worldwide. ${ }^{11}$ It has a high prevalence $(5-30 \%)$ in the tropical and sub-tropical regions of the world, including Africa, Asia, the Middle East, the Mediterranean, and Papua New Guinea. ${ }^{22,23}$ In the U.S., Afro-American males are commonly affected, with a prevalence of $10 \% .{ }^{23}$ The island of Sardinia is one of the areas with the highest prevalence, with rates of between 8 and 15\%.12-18

The geographic distribution of G6PD deficiency is highly correlated with the distribution of current or past malaria endemicity. This finding might be the result of a balanced polymorphism conferring resistance to infection with falciparum malaria. ${ }^{11}$ Furthermore, recent research has found supportive evidence for protection against ischemic heart and cerebrovascular disease, RVO, NAION, and colorectal cancer in G6PD deficient individuals. ${ }^{14,16,19-21}$ Overall, these data seem to suggest that G6PD deficiency may have a protective effect against the development of various age-related diseases.
The main risk factors for the development of late-stage AMD include ageing, genetics, ethnicity, and oxidative stress. ${ }^{3-9}$ Tobacco smoking is the main modifiable risk factor consistently identified in many studies; 6,24 thus, stopping smoking is strongly recommended in patients at risk for AMD. A number of population-based and case-control studies have investigated the correlation between AMD, systemic hypertension, and other cardiovascular diseases..$^{25-32}$ These studies have reported conflicting results.

Little is known about the role of G6PD deficiency in the pathogenesis of AMD. To the best of our knowledge, we are unaware of any previous investigation exploring a possible relationship between late-stage AMD and G6PD deficiency. In theory, a decrease in NADPH production might paradoxically result in protection against oxidative stress, as reported by a recent survey associating high G6PD activity and elevated NDAPH levels with endothelial and vascular dysfunction. ${ }^{33}$ In fact, G6PD-derived NADPH, a cofactor for NADPH oxidase, enhances superoxide anion generation, thus increasing oxidative stress. ${ }^{33}$ G6PD deficiency might also offer protection against choroidal 
microangiopathy because of the decreased cholesterol synthesis. ${ }^{15}$

In our study, we found that late-stage AMD patients and cataract controls without AMD had similar values of G6PD prevalence $(8.9 \%$ and $10.1 \%$, respectively). Stepwise logistic regression analysis showed that G6PD deficiency has no significant protective effect against AMD, nor is a risk factor for this degenerative macular disorder. Even though there does not appear to be a substantial protective or enhancing effect of G6PD deficiency on the development of AMD, there is still the possibility of a less pronounced effect that is missed because of a type II error due to the relatively small sample size, largely dependent on the incidence of AMD. Indeed, if we, hypothetically, increased by 60 times the number of cases and controls (4,740 instead of 79) and maintained the same prevalence rates of G6PD deficiency as above, we would find a statistically significant protective effect of G6PD deficiency on late-stage $\mathrm{AMD}(\mathrm{OR}=0.86 ; 95 \% \mathrm{CI}=0.75-0.99 ; \mathrm{P}=$ 0.036).

Our investigation also shows that late-stage AMD is significantly associated with higher values of diastolic blood pressure and LDL, even though, particularly for LDL, the OR is pretty small. Our results are consistent with former studies identifying systemic hypertension and serum cholesterol levels as risk factors for $\mathrm{AMD}, 25,28,32,34-37$ but conflicting with others. ${ }^{26,37,38}$ Lipid metabolism has long been hypothesized to be important in the pathogenesis of AMD. ${ }^{39}$ Indeed, lipid deposits in Bruch's membrane represent at least $40 \%$ of the volume of drusen. ${ }^{40}$

A correlation between systemic hypertension, cholesterol, and AMD would suggest the presence of shared risk factors for cardiovascular disease and AMD, and may support the hypothesis of a similar pathogenesis. However, in the present survey, AMD patients and control subjects without AMD had similar rates of cardio- and cerebro-vascular disorders, a result contrasting with the former hypothesis.

In our study, we found that patients with AMD had a significantly lower WBC count; furthermore, AMD risk was significantly associated with lower values of WBC count. Previous epidemiological studies have shown conflicting results regarding the association between WBC count and AMD. Whereas multiple studies have reported correlations between higher WBC counts and an increased risk of AMD, $36,41,42$ other studies have failed to find such an association. ${ }^{43-45}$ This evidence is further complicated by our finding, showing an inverse correlation, i.e. that a higher WBC count is associated with a lower risk of AMD. Overall, these results suggest that the role of leukocyte count in AMD is far from clear.

In our survey, patients with AMD had significantly lower values of AST, and AMD risk was significantly associated with lower AST values. We are unaware of any former study exploring a possible relationship between AMD and transaminases. The significance of our finding, implying that higher AST values may have a protective effect against AMD, remains obscure and needs further investigation.

It is well known that smoking significantly increases the risk of AMD. Nevertheless, in our study, AMD patients and cataract controls without AMD had similar rates of smoking. This result does not come as a surprise, because smoking is a modifiable risk factor not only for AMD, but also for senile cataract. ${ }^{46-48}$

In our investigation, the controls were selected among patients undergoing cataract surgery. We feel strongly that this strategy did not lead to a selection bias. ${ }^{49}$ Actually, the prevalence rate $(10.1 \%)$ of G6PD deficiency in the control group was the same as in the male Sardinian population, $13,17,18$ a finding consistent with former large studies showing that G6PD deficient patients do not have a higher risk of developing cataract. 17,50

Our study has several important limitations, including its cross-sectional design and the relatively small sample size. Furthermore, it was restricted to a limited, genetically homogeneous group of patients (i.e. those of Sardinian descent). Therefore, our findings may not be applicable to AMD patients of non-Sardinian ancestry. Last, but not least, even though both wet and dry forms of AMD have common underlying pathological features and causes, we analyzed a small number of patients with geographic atrophy.

In conclusion, our results suggest that G6PD deficiency has no protective effect against AMD, nor is a risk factor for this degenerative macular disorder. On the other hand, AMD was significantly associated with higher values of diastolic blood pressure and LDL and lower values of WBC count and AST. These findings need to be confirmed by larger scale studies, also involving patients of non-Sardinian ancestry.

\section{Acknowledgements}

This study was partially supported by a grant funded by the "Regione Autonoma della Sardegna," Italy, according to the LR August 7, 2007, n. 7 (\#RAS 2010, CRP-25871 ANTONIO PINNA). The funding organization had no role in the design or conduct of this research.

This paper was in part presented as a Scientific Poster (\# 2922247) at the 2018 ARVO Annual Meeting, April 29 - May 3, 2018, Honolulu, Hawaii (USA). 


\section{Competing Interests}

The authors have declared that no competing interest exists.

\section{References}

1. Friedman DS, O'Colmain BJ, Muñoz B, Tomany SC, McCarty C, de Jong PT, Nemesure B, Mitchell P, Kempen J; Eye Diseases Prevalence Research Group. Prevalence of age-related macular degeneration in the United States. Arch Ophthalmol. 2004; 122: 564-72.

2. Age-Related Eye Disease Study Research Group. A randomized, placebo-controlled, clinical trial of high-dose supplementation with vitamins $\mathrm{C}$ and $\mathrm{E}$, beta carotene, and zinc for age-related macular degeneration and vision loss: AREDS report number 8. Arch Ophthalmol. 2001; 119: 1417-36.

3. Beatty S, Koh H, Phil M, Henson D, Boulton M. The role of oxidative stress in the pathogenesis of age-related macular degeneration. Surv Ophthalmol. 2000; 45: 115-34.

4. Despriet DD, Klaver CC, Witteman JC, Bergen AA, Kardys I, de Maat MP, Boekhoorn SS, Vingerling JR, Hofman A, Oostra BA, et al. Complement factor $\mathrm{H}$ polymorphism, complement activators, and risk of age-related macular degeneration. JAMA. 2006; 296: 301-9.

5. Khan JC, Thurlby DA, Shahid H, Clayton DG, Yates JR, Bradley M, Moore AT, Bird AC; Genetic Factors in AMD Study. Smoking and age related macular degeneration: the number of pack years of cigarette smoking is a major determinant of risk for both geographic atrophy and choroidal neovascularisation. Br J Ophthalmol. 2006; 90: 75-80.

6. Yang Z, Camp NJ, Sun H, Tong Z, Gibbs D, Cameron DJ, Chen H, Zhao $Y$, Pearson E, Li X, et al. A variant of the HTRA1 gene increases susceptibility to age-related macular degeneration. Science. 2006; 314: 992-3.

7. Yates JR, Sepp T, Matharu BK, Khan JC, Thurlby DA, Shahid H, Clayton DG, Hayward C, Morgan J, Wright AF, et al. Complement C3 variant and the risk of age-related macular degeneration. N Engl J Med. 2007; 357: 553-61

8. Schmidl D, Garhöfer G, Schmetterer L. Nutritional supplements in age-related macular degeneration. Acta Ophthalmol. 2015; 93: 105-21.

9. Hong N, Shen Y, Yu CY, Wang SQ, Tong JP. Association of the polymorphism $\mathrm{Y} 402 \mathrm{H}$ in the $\mathrm{CFH}$ gene with response to anti-VEGF treatment in age-related macular degeneration: a systematic review and meta-analysis. Acta Ophthalmol. 2016; 94: 334-45.

10. Kletzien RF, Harris PK, Foellmi LA. Glucose-6-phosphate dehydrogenase: a "housekeeping" enzyme subject to tissue-specific regulation by hormones, nutrients, and oxidant stress. FASEB J. 1994; 8: 174-81.

11. Beutler E. G6PD deficiency. Blood. 1994; 84: 3613-36.

12. Martinez di Montemuros F, Dotti C, Tavazzi D, Fiorelli G, Cappellini MD. Molecular heterogeneity of glucose-6-phosphate dehydrogenase (G6PD) variants in Italy. Haematologica. 1997; 82: 440-5.

13. Maida A, Pettinato S, Bo G. Clinical manifestations of favism and G6PD deficiency: epidemiological survey in the province of Sassari (Sardinia, Italy). Haematologica, 1973; 58: 1265-82.

14. Cocco P, Todde P, Fornera S, Manca MB, Manca P, Sias AR. Mortality in a cohort of men expressing the Glucose-6-Phosphate Dehydrogenase deficiency. Blood. 1998; 91: 706-9.

15. Batetta B, Bonatesta RR, Sanna F, Putzolu M, Mulas MF, Collu M, Dessì S. Cell growth and cholesterol metabolism in human glucose-6-phosphate dehydrogenase deficient lymphomononuclear cells. Cell Prolif. 2002; 35: 143-54.

16. Pinna A, Carru C, Solinas G, Zinellu A, Carta F. Glucose-6-phosphate dehydrogenase deficiency in retinal vein occlusion. Invest Ophthalmol Vis Sci. 2007; 48: 2747-52.

17. Pinna A, Pes A, Zinellu A, Carta A, Solinas G. Glucose-6-phosphate dehydrogenase (G6PD) deficiency and senile cataract in a Sardinian male population, Italy. Ophthalmic Epidemiol. 2009; 16: 395-9.

18. Pes GM, Errigo A, Bitti A, Dore MP. Effect of age, period and birth-cohort on the frequency of glucose-6-phosphate dehydrogenase deficiency in Sardinian adults. Ann Med. 2018; 50: 68-73.

19. Dore MP, Davoli A, Longo N, Marras G, Pes GM. Glucose-6-phosphate dehydrogenase deficiency and risk of colorectal cancer in Northern Sardinia: A retrospective observational study. Medicine (Baltimore). 2016; 95: e5254.

20. Pes GM, Bassotti G, Dore MP. Colorectal Cancer Mortality in Relation to Glucose-6-Phosphate Dehydrogenase Deficiency and Consanguinity in Sardinia: A Spatial Correlation Analysis. Asian Pac J Cancer Prev. 2017; 18: 2403-7.
21. Pinna A, Solinas $G$ Masia $C$, Zinellu A, Carru C, Carta A. Glucose-6-phosphate dehydrogenase (G6PD) deficiency in nonarteritic anterior ischemic optic neuropathy in a Sardinian population, Italy. Invest Ophthalmol Vis Sci. 2008; 49: 1328-32.

22. WHO Working Group. Glucose-6-phosphate dehydrogenase deficiency. Bull World Health Organ. 1989; 67: 601-11.

23. Ruwende C, Hill A. Glucose-6-phosphate dehydrogenase deficiency and malaria. J Mol Med. 1998; 76: 581-8.

24. Tan JS, Mitchell P, Kifley A, Flood V, Smith W, Wang JJ. Smoking and the long-term incidence of age-related macular degeneration: the Blue Mountains Eye Study. Arch Ophthalmol. 2007; 125: 1089-95.

25. Age-Related Eye Disease Study Research Group. Risk factors associated with age-related macular degeneration. A case-control study in the age-related eye disease study: Age-Related Eye Disease Study report number 3. Ophthalmology. 2000; 107: 2224-32.

26. Delcourt C, Michel F, Colvez A, Lacroux A, Delage M, Vernet MH. Associations of cardiovascular disease and its risk factors with age-related macular degeneration: the POLA Study. Ophthalmic Epidemiol. 2001; 8: 237-49.

27. McCarty CA, Mukesh BN, Fu CL, Mitchell P, Wang JJ, Taylor HR. Risk factors for age-related maculopathy: the Visual Impairment Project. Arch Ophthalmol. 2001; 119: 1455-62.

28. Hyman L, Schachat AP, He Q, Leske MC, Age-Related Macular Degeneration Risk Factors Study Group. Hypertension, cardiovascular disease, and age-related macular degeneration. Arch Ophthalmol. 2000; 118: 351-8.

29. Klein R, Deng Y, Klein BE, Hyman L, Seddon J, Frank RN, Wallace RB, Hendrix SL, Kuppermann BD, Langer RD, et al. Cardiovascular disease, its risk factors and treatment, and age-related macular degeneration: Women's Health Initiative Sight Exam ancillary study. Am J Ophthalmol. 2007; 143: 473-83.

30. Keilhauer CN, Fritsche LG, Guthoff R, Haubitz I, Weber BH. Age-related macular degeneration and coronary heart disease: evaluation of genetic and environmental associations. Eur J Med Genet. 2013; 56: 72-9.

31. Fernandez AB, Wong TY, Klein R, Collins D, Burke G, Cotch MF, Klein B, Sadeghi MM, Chen J. Age-related macular degeneration and incident cardiovascular disease: the Multi-Ethnic Study of Atherosclerosis. Ophthalmology. 2012; 119: 765-70.

32. Olea JL, Tunon J. Patients with neovascular age-related macular degeneration in Spain display a high cardiovascular risk. Eur J Ophthalmol. 2012; 22: 404-11.

33. Gupte SA. Glucose-6-phosphate dehydrogenase: a novel therapeutic target in cardiovascular diseases. Curr Opin Investig Drugs. 2008; 9: 993-1000.

34. Fan Q, Maranville JC, Fritsche L, Sim X, Cheung CMG, Chen LJ, Gorski M, Yamashiro K, Ahn J, Laude A, et al. HDL-cholesterol levels and risk of age-related macular degeneration: a multiethnic genetic study using Mendelian randomization. Int J Epidemiol. 2017; 46: 1891-902.

35. Jonasson F, Fisher DE, Eiriksdottir G, Sigurdsson S, Klein R, Launer LJ, Harris T, Gudnason V, Cotch MF. Five-year incidence, progression, and risk factors for age-related macular degeneration: the age, gene/environment susceptibility study. Ophthalmology. 2014; 121: 1766-72.

36. Klein R, Klein BE, Franke T. The relationship of cardiovascular disease and its risk factors to age-related maculopathy. The Beaver Dam Eye Study. Ophthalmology. 1993; 100: 406-14.

37. Tan JS, Mitchell P, Smith W, Wang JJ. Cardiovascular risk factors and the long-term incidence of age-related macular degeneration: the Blue Mountains Eye Study. Ophthalmology. 2007; 114: 1143-50.

38. Klein R, Myers CE, Buitendijk GH, Rochtchina E, Gao X, de Jong PT, Sivakumaran TA, Burlutsky G, McKean-Cowdin R, Hofman A, et al. Lipids, lipid genes, and incident age-related macular degeneration: the three continent age-related macular degeneration consortium. Am J Ophthalmol. 2014; 158: 513-524e3.

39. Swaroop A, Chew EY, Rickman CB, Abecasis GR. Unraveling a multifactorial late-onset disease: from genetic susceptibility to disease mechanisms for age-related macular degeneration. Annu Rev Genomics Hum Genet. 2009; 10: 19-43.

40. Curcio CA, Presley JB, Millican CL, Medeiros NE. Basal deposits and drusen in eyes with age-related maculopathy: evidence for solid lipid particles. Exp Eye Res. 2005; 80: 761-75.

41. Yasuda M, Kiyohara Y, Hata Y, Arakawa S, Yonemoto K, Doi Y, Iida M, Ishibashi T. Nine-year incidence and risk factors for age-related macular degeneration in a defined Japanese population the Hisayama study. Ophthalmology. 2009; 116: 2135-40.

42. Shankar A, Mitchell P, Rochtchina E, Tan J, Wang JJ. Association between circulating white blood cell count and long-term incidence of age-related macular degeneration: the Blue Mountains Eye Study. Am J Epidemiol. 2007; 165: 375-82. 
43. Inhoffen $W$, Nüssgens Z. Rheological studies on patients with posterior subretinal neovascularization and exudative age-related macular degeneration. Graefes Arch Clin Exp Ophthalmol. 1990; 228: 316-20.

44. Wu KH, Tan AG, Rochtchina E, Favaloro EJ, Williams A, Mitchell P, Wang JJ. Circulating inflammatory markers and hemostatic factors in age-related maculopathy: a population-based case-control study. Invest Ophthalmol Vis Sci. 2007; 48: 1983-8.

45. Gopinath B, Flood VM, Rochtchina E, Wang JJ, Mitchell P. Homocysteine, folate, vitamin B-12, and 10-y incidence of age-related macular degeneration. Am J Clin Nutr. 2013; 98: 129-35.

46. Robman L, Taylor H. External factors in the development of cataract. Eye. 2005; 19: 1074-82.

47. Christen WG, Manson JE, Seddon JM, Glynn RJ, Buring JE, Rosner B, Hennekens $\mathrm{CH}$. A prospective study of cigarette smoking and risk of cataract in men. JAMA. 1992; 268: 989-93.

48. Klein BE, Klein RE, Lee KE. Incident cataract after a five-year interval and lifestyle factors: the Beaver Dam eye study. Ophthalmic Epidemiol. 1999; 6: 247-55.

49. Pinna A, Contini EL, Carru C, Solinas G. Glucose-6-phosphate dehydrogenase deficiency and diabetes mellitus with severe retinal complications in a Sardinian population, Italy. Int J Med Sci. 2013; 10: 1907-13.

50. Meloni T, Carta F, Forteleoni G, Carta A, Ena F, Meloni GF. Glucose 6-phosphate dehydrogenase deficiency and cataract of patients in Northern Sardinia. Am J Ophthalmol. 1990; 110: 661-4. 